\title{
Recent Applications of 3d Printing and Its Challenges - A Review
}

\author{
P. Sivasankaran \\ Associate Professor/Department of Mechanical \\ Engineering/Manakula Vinaayagar Institute of Technology, \\ Pondicheery - 605 107, INDIA
}

\author{
B. Radjaram \\ Professor and Head/Department of Mechanical \\ Engineering/Manakula Vinayagar Institute of Technology, \\ Pondicherry - 605 107, INDIA.
}

\begin{abstract}
In the continuous time of collecting 3D Printing has become the most critical advancement for conveying the parts by included substance development. This advancement is remarkable comparable to subtractive collecting methodology which is done already. In this advancement there is no material setback while building the parts thusly the name given to the development is included substance manufacturing. we can exhibit the parts as a model before amassing structures so any further changes or updates are to be made will be clarified dynamically clarify by using 3D printing. This development is somewhat solidly related to brisk prototyping techniques. Use of $3 \mathrm{D}$ printing has wide range in various applications in this study paper try has been to address the usage of 3D Printing machine in medicine's, Défense, transport, and vehicle creating ventures. Without a doubt, even in post-COVID conditions, 3D printing machines are in huge enthusiasm to make cover to shield society from the pandemic disease.
\end{abstract}

Keywords: $3 D$ Printing, Rapid prototyping , Additive manufacturing.

\section{INTRODUCTION}

Added substance Manufacturing (AM) otherwise called 3D printing constructs three-Dimensional (3-D) strong articles. The object is fabricated layer-by-layer utilizing various materials such as polymers, composites, clay and metallic glues contingent upon the prerequisite utilizing computerized information from a PC. Fast prototyping, the primary arranged AM was created to quickly manufacture models. Stereolithography (STL) was the primary procedure that rose in the late eighties. In the long run, as this innovation extended to fabricate the last items, it was named as fast assembling (Ghazy, 2012). AM is an imaginative innovation which has the capacity to upset the worldwide assembling industry. Siemens explore bunch assesses that $3 \mathrm{D}$ printing will get $400 \%$ quicker and half less expensive in the following five a long time (Siemens and Zistl, 2014). In 2012, USA built up National Additive Manufacturing Innovation Institute (NAMII), presently known as America Makes in Youngstown, Ohio with government financing of $\$ 50$ million. It is driven by National Center for Defense Manufacturing and Machining.

The strategic of this organization is to quicken and advance AM(Additive Manufacturing) and 3D printing to expand USA's worldwide fabricating intensity (U.S. Division of Protection, Manufacturing Technologies Program, 2012). Commonly, any AM (Additive Manufacturing) procedure incorporates a blend of the accompanying eight stages:

1. Conceptualization and CAD model

2. Change to STL group
3. Move to AM gear and control of STL document

4. Machine arrangement

5. Fabricate the part

6. Evacuation and cleanup of the fabricated part

7. Post preparing of the part

8. Application (Gibson et al., 2012)

AM (Additive Manufacturing) has been given various names, which incorporate; layered assembling, added substance manufacture, 3D printing, added substance procedures, computerized fabricating, added substance forms, free structure manufacture and added substance layered producing (Ghazy, 2012). As indicated by ASTM, AM defined as the procedure of joining materials to make objects from 3D model information as a rule layer-by-layer, rather than subtractive assembling innovations, for example, conventional fabricating" (Standard, 2012). There are extraordinary sorts of added substance fabricating forms, which incorporate; photograph polymerization process (Jacobs and Francis, 1992), expulsion based frameworks (Comb et al., 1994), powder bed combination forms (Beaman et al., 1997), (Cormier et al., 2004), material flying procedures (Engstrom, 2012a), fastener flying procedures (Engstrom, 2012a), bar statement forms (Balla et al., 2008), sheet cover forms (Feygin and Freeform, 1991) and direct compose advances (Pique and Chrisey, 2001). AM has an assortment of advantages over the conventional and subtractive fabricating techniques. A portion of the significant advantages incorporate high level of plan opportunity, proficiency, multifaceted nature and adaptability, diminished get together and unsurprising creation, support for green assembling activities, exact physical replication (Grimm, n.d.), (Diminish, 2012). Because of the quick advancement of the innovation, AM has enlarged its applications to numerous fields, for example, gadgets, clinical, aviation, development, clinical industry, design, food industry, car, oceanography and research (Wimpenny et al.,) . Thus, 3D Printing is one of the emerging fields in the area of design and manufacturing which enables the reliability of product design and production.

\section{LITERATURE REVIEW}

\subsection{D Printing in Manufacturing applications:}

Hyungjoo kim [1]

Description: 3D printing, can be alluded as added substance fabricating, which manages model development and creation of definite items for various assortment of utilizations. This innovation is engaged in two unique 
portions of the market: very good quality modern printing and lower-end buyer printing (PwC, 2014). Furthermore, as per Faludi, et al. (2015), the 3D printing industry is strolling towards a future where legitimate amassing will be otherworldly. Notwithstanding, not many examinations have concentrated on advertise investigation and configuration highlighting with respect to $3 \mathrm{D}$ printing. Also, in the past less number of consideration is worried on the new utilization of this innovation. As per maker concern the fact of the matter is to think about the market ability of 3D printing advancement and its troublesome structures.

Conclusion: Moreover, this innovation has all the more testing highlights for various assortment of reasons, it is supposed to be an imaginative and feasible development. Moreover, manageable materials and open source programming easy to use bundles can aid the future utilization of practical plan utilizing 3D printing innovation. Along these lines, this examination will give data to individuals in clamorous circumstances recently rejected from the business world and the academic network, and urge their responsibilities to the improvement of 3D printing for successful thing structure and model creation.

\section{Santhosh kumar parupelli [2]}

Description :Additive assembling (AM) can be named as $3 \mathrm{D}$ printing this is depicted as mechanical apparatus that fabricates three-dimensional (3-D) strong articles. It manufactures high normalized Modified 3D objects with complex geometries and included functional plans can be made using 3D printing.

Conclusion :Rapid protyping is the further headway of Additive Manufacturing (AM) to an assembling innovation equipped for delivering practical end-client items for various applications. This paper gives a nitty gritty outline of all the AM(Additive Manufacturing) innovations ordered under the accompanying procedures: Photo polymerization, expulsion frameworks, powder bed combination, flying procedures, coordinated vitality testimony, sheet cover and cross breed and direct compose AM. Further, the paper gives bits of knowledge about the critical progressions in a various scope of fields which incorporate gadgets, clinical industry, aviation, development, design, food industry and the car business. This survey will elevate AM advances to analysts and enterprises with ongoing progressions and possibilities of AM procedures, materials and abilities.

\section{Eda Hazan baran [3]}

Description : Polylactic corrosive (PLA) fibers is one of the mainstream material utilized as a thermoplastic source in the 3D printing field by the "Merged Deposition Modeling" methodology in the prior decade. The PLA grandstand is anticipated subject to promote potential to show up at 5.2 billion US dollars in 2020 for the aggregate of its advanced vocations. On the other hand, 3D printing is a developing advancement that has an enormous money related potential in various scarcely any ventures where PLA is one of the essential choices as the source polymer on account of its effortlessness of printing, earth welcoming nature, gleam and multicolour appearance properties.

Conclusion : The objective of this study is to report and comment on the current composing which was circulated on a shallow level adjustment of the 3D printed PLA questions in order to consider new to be as applied in the additional substance creating industry.

\subsection{D Printing in Medical applications: \\ Mohd Javid [1]}

Description : Innumerable assessment paper on Medical cases using Additive collecting considered. Different uses of included substance delivering progresses in the clinical region explored for giving the forefront and heading of the unforeseen development.

Conclusion: Paper deals with the composing review of the Medical utilization of Additive Manufacturing and its future.

\section{Don Hoang [2]}

Description : In this review, the different and extending usages of 3D printing have been presented. Additionally, we have given an establishment on RP and a part of the examinations when starting with 3D printing, for instance, imaging, programming, printing materials, purging of printing materials, and cost and time necessities.

Conclusion : In this audit, the unique and developing utilizations of $3 \mathrm{D}$ printing have been introduced. In like manner, we have given a foundation on RP and a touch of the assessments when beginning with $3 \mathrm{D}$ printing, for example, imaging, programming, printing materials, purging of printing materials, and cost and time necessities. Anna Aimar [3]

Description : In this audit, the different and developing employments of 3D printing have been introduced. In like manner, we have given a foundation on RP and a touch of the musings when beginning with 3D printing, for example, imaging, programming, printing materials, cleansing of printing materials, and cost and time necessities. The usage of 3Dprinting in clinical framework has expanded exponentially, as obvious by the measure of scatterings over the range of continuous years.

Conclusion: 3D printing in clinical field and structure needs to think outside the standard for changing the human services. 'e three primary mainstays of this new innovation are the capacity to treat more individuals where it recently was not plausible, to acquire results for patients and less time required under the immediate instance of clinical masters. In scarcely any words, 3D printing comprises in "empowering specialists to treat more patients, without relinquishing results" [94]. 'hence, similar to any new innovation, 3D printing has presented numerous points of interest and conceivable outcomes in the clinical field. Every particular case wherein 3D printing has discovered application appeared in this examination is a showing of this. In any case, it must be joined by a refreshed and current enactment so as to ensure its right use.

\subsection{D Applications in Aircrafts:}

Brogan Rylands [1]

Description : 3D printing is acknowledged by various people to be the accompanying mechanical change. The 
development is starting at now sent in progress. Regardless, deftly chain composing is still in its beginning periods with respect to this topic, despite $3 \mathrm{D}$ printings radical impact on smoothly chains.

Conclusion : There is a lot of intricacy around 3D printing, which achieves the need to basically reengineer esteem streams. It is a synergistic endeavor over the entire association and there are numerous angles to be thought of, stemming from a business and specialized point of view as well as social and ecological viewpoints that require thought. This paper gave an outline of what $3 \mathrm{D}$ printing is, instances of enterprises that it is as of now conveyed, by they way it can impact gracefully chains and viewpoints for thought before appropriation.

\section{Sunil C.Joshi [2]}

Description: Incredibly 3D printing has energized the universe of aviation. This paper takes the load of the mainstream 3D printing forms in aviation. Purposes behind their notoriety .over the conventional assembling forms are stayed upon. Materials grew uniquely for aviation applications alongside their attributes are talked about. Progressing exercises identified with 3D printing at different organizations and associations around the globe are investigated.

Conclusion : 3D printing is unquestionably changing the universe of assembling, even in a generally progressed and complex industry like avionic business. This industry works around 2 essential guideline necessities - low weight and high wellbeing.

\section{Wouter Boon [3]}

Description: Shopper 3D printing is on the ascent and can possibly fundamentally change the vehicle and coordinations division. Current writing on 3D printing and transport contemplates doesn't give a methodical model of the effect of 3D imprinting on transport and related (strategy pertinent) zones, for example, traffic security, area choices, openness and ecological impacts .

Conclusion : This paper aims to explore the impact of 3D printing on transport and transport-related impacts on society, including $\mathrm{CO} 2$ emissions, traffic-related safety victims and accessibility. To do so, we develop an initial conceptual model consisting of "wants and needs of consumers", "location decisions" and "transport resistance", and their impacts on transport technologies, transport volumes, safety, the environment and accessibility. We based the model on a literature review and refined the model through two rounds of consulting experts.

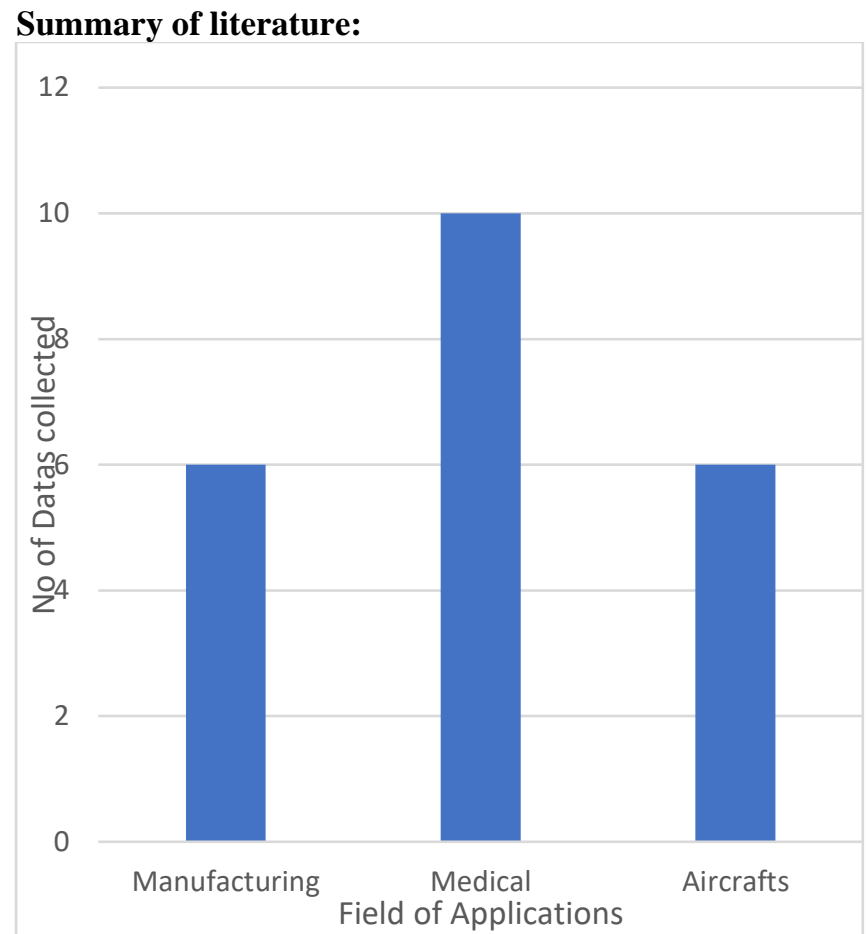

Fig 2.4 . Statistical information of Literature data on 3D Printing

CONCLUSION:

Based on the review of literature on $3 \mathrm{~d}$ printing applications such as Manufacturing, Medicine and Aircrafts it is observed from the statistical information ( Fig.2.4.) more rapid advancements are carried out in medical applications using 3D printing technology even today in pandemic situation use of 3D printed masks are available in market as per customer specification in higher demand . so medical field as proven better as compared to manufacturing and aerospace in future more several things are likely to happen in other remaining areas. Hence in this paper attempt has been made to collect review data from different applications of 3D Printing technology.

\section{CRITIQUE OF REVIEW ON 3D PRINTING IN CONSTRUCTION:}

Research in the territory of Additive Manufacturing, and specifically, Additive Manufacturing for development, is extremely rich, as it very well may be seen from the high number of references refered to underneath. This paper offers a complete survey of writing identified with 3D imprinting in development. It tends to a distinguished hole in comparable audit papers and offers a more extensive inclusion of specialized and administrative difficulties. The paper distinguished twenty difficulties and characterized them into seven classes. Thus, dangers are distinguished and ordered into six classes. This covers a significant writing hole and offers new headings of research concentrating on the specialized angles as well as on the administrative viewpoints. Also, the paper talks about and assesses the various frameworks of 3D imprinting in development. In view of the explored writing, the primary ends are as per the following:

$3 \mathrm{D}$ printing can possibly change the development business. $3 \mathrm{D}$ printing, alongside propels in Industry 4.0, has a high 
potential to prompt a progressively productive and manageable development. In spite of the significant advances in $3 \mathrm{D}$ printing innovation, as detailed in the writing, the utilization of $3 \mathrm{D}$ imprinting in development is still in the early stages stage. There is far for it to arrive at its latent capacity and warrant a boundless usage. Research is as yet in progress in a few territories particularly in the mechanical and material perspectives. The primary test is adjusting the automated framework to enormous scope development activities, for example, manors and elevated structure. Regularly, the mechanical framework is custom fitted to little and limited workspace. In development, the automated framework should be adjusted to a bigger and progressively open workspace. $3 \mathrm{D}$ printing requires explicit material properties. Most assessed investigate concentrated on meeting the requirements of the $3 \mathrm{D}$ printer. Be that as it may, more research is expected to meet the structure and quality limitations notwithstanding the 3D printer requirements. The confinements of the $3 \mathrm{D}$ printer innovation, the nature of the last item, and the multifaceted nature of the development procedure are the fundamental explanations behind the low appropriation pace of 3D imprinting in development. 3D printing will be a piece of things to come of the development business. Be that as it may, a few moves despite everything should be tended to before 3D printing can turn into a feasible arrangement. Dangers related with this new innovation were distinguished and grouped dependent on their sources. These dangers should be surveyed, so as to consider them during the arranging phase of the development venture.

\section{REFERENCES:}

[1] Hyungjoo kim , Market Analysis and the future of Sustainable Design using 3D Printing Technology , Archives of Design Research , PP :23-35, 2017

[2] Santhosh kumar parupelli and salil desai , A comprehensive review of additive manufacturing (3D Printing ): Processes ,Applications and Future Potential, American Journal of Applied sciences ,PP:244 - 272, 2019.

[3] Eda Hazan baran and H.Yildirium Erbil , Surface Modification of 3D Printed PLA objects by Fused Deposition Modeling :A Review , Colloids and interfaces, PP:1-25, 2019.

[4] Mohd Javid ,Abid Haleem , Additive manufacturing applications in medical cases : A Literature based review,Alexandria Journal of Medicine, PP: 411- 422,2017.

[5] Don hong, David Perrault ,Milan Stevanoic, Alidad Ghiassi Surgical Applications of three - dimensional printing : a review of the current literature and how to get started, Review article on Innovations and Technology in Surgery ,PP: 1-19, 2016.

[6] Anna Aimar, Augusto Palermo and Bernardo Innocenti ,The role of 3D Printing in Medical Applications: A State of the art , Journal of Health care Engineering , PP:1-11, 2019.

[7] Rylands, B., Bohme, T., Gorkin III, R., Fan, J. \& Birtchnell, T, 3D Printing - To print or not to print? Aspects to consider before adoption - A supply chain perspective, Australian institute for innovative materails, PP : 1-12, 2015.

[8] Sunil .C. Joshi and Abdullah .A.Sheikh, 3D Printing in aerospace and its long term sustainability , Journal of Virtual and Physical Prototyping, PP: 1- 18, 2015.

[9] Wouter boon and Bert van wee, Influence of 3D Printing on transport : a theory and experts judgement based conceptual model , Journal of transport reviews , PP: 1- 21, 2017. 